\title{
Study on the Microstructure and Texture of 3003 Aluminum Sheets Rolled by Laser-Textured Roll
}

\author{
Chunbo Cai, ${ }^{1}$ Zesheng Ji, ${ }^{1}$ Huajun Zhang, ${ }^{1}$ and Guojun Wang ${ }^{2}$ \\ ${ }^{1}$ School of Materials Science and Engineering, Harbin University of Science and Technology, 4 Linyuan Road, Harbin 150040, China \\ ${ }^{2}$ Northeast Light Alloy Co. Ltd., Harbin 150060, China \\ Correspondence should be addressed to Chunbo Cai, caichunbo@126.com
}

Received 22 October 2008; Revised 13 February 2009; Accepted 22 March 2009

Recommended by Katsuyoshi Kondoh

In order to improve the surface quality and formability of 3003 aluminum alloy sheet, laser-textured rolls are used in cold rolling. The influences of the cold rolling procedures with conventional and laser-textured rolls on the evolution of microstructure and texture were studied by the means of microstructural observations and X-ray texture analysis. Experimental results show that the microstructures are similar besides the samples rolled with laser-textured rolls containing a relatively larger amount of shear bands. The sheets deformed with conventional rolls have developed the typical rolling textures of FCC metals, which consist of Bs, Cu, and $\mathrm{S}$ components. However, the rolling textures of the sheets rolled with laser-textured rolls are comparatively weak, and the shear texture $\{001\}\langle 110\rangle$ is developed on the surface layer, but not observed in the intermediate layer of the sheet. The intensity of the rotated cube orientation increases with the increase of rolling reduction and then decreases after $90 \%$ rolling reduction.

Copyright (C) 2009 Chunbo Cai et al. This is an open access article distributed under the Creative Commons Attribution License, which permits unrestricted use, distribution, and reproduction in any medium, provided the original work is properly cited.

\section{Introduction}

It is well known that the surface morphology and roughness of cold roll can influence the surface morphology, formability, and deep drawing properties of bands. Several studies have reported that the laser-textured rolls (LTRs) can improve deep drawing properties and surface morphology of the steel sheets $[1,2]$. Recently, there has been an increased interest in using LTR as a method to produce steel and aluminum sheets with high quality and good surface morphology [3, 4]. But studies characterizing the effect of LTR technology on the microstructure and texture of sheets are limited. In rolling processing by LTR, textured roll mills the sheet, and the morphology of roll is copied to the sheet. Due to the high surface roughness of LTR, the friction between the rolls and the sheets in LTR case is higher than that in conventional rolls (CRs) case. The microstructure and deformation texture of the sheets rolled by LTR differ from that of the sheets rolled by CR. In order to improve the formability of LTR, it is necessary to control its microstructure and deformation texture by adjusting processing parameters. One of the adjustable processing parameters is the thickness reduction of cold rolling which affects the evolution of microstructure and texture.

The effect of cold deformation on the evolution of microstructure and texture during the rolling of aluminium and its alloys has been the subject of the research by metallurgists, since it is one of the main factors which are responsible for the anisotropy of final sheet products $[5,6]$. In earlier studies, significant progresses have been achieved in the aspect of deformation textures, covering the entire ranges from the typical pure metal texture with the characteristic copper orientation $\{112\}\langle 111\rangle$ to textures with a pronounced brass orientation $\{011\}\langle 211\rangle[7,8]$. Many factors such as alloy composition, initial microstructure and texture prior to rolling, rolling reduction, and rolling condition influence the deformation textures [9]. In the recent years, great progress has been made in the studies about deformation texture of aluminum alloy. While these researches have focused primarily on the effects of process conditions on deformation texture in CR rolled sheet, little has been done to investigate sheets produced with LTR.

In this study, rolling processes with $\mathrm{CR}$ and LTR are carried out to compare the microstructure and texture in 


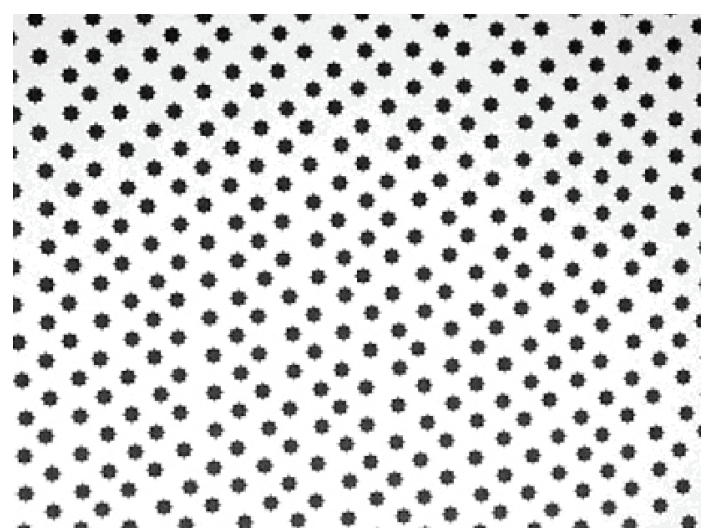

Figure 1: Textured lattice pattern.

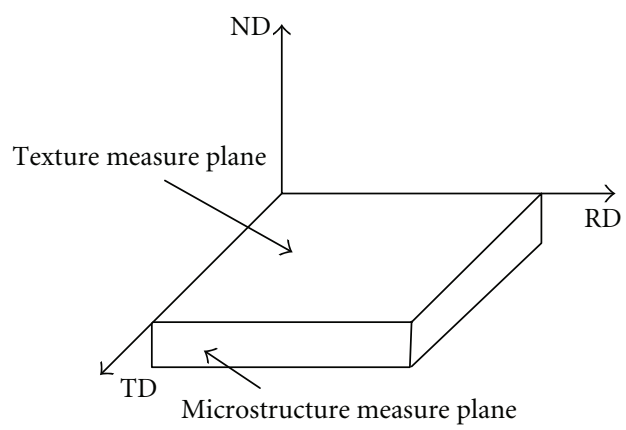

FIGURE 2: Specimen geometry of 3003 alloy sheet.

a commercial 3003 alloy; a typical aluminum alloy used in can body applications.

\section{Experimental Procedure}

The materials used in this work were commercially produced hot bands of CC 3003 alloy, its chemical composition, in mass fraction, was 0.6 pct $\mathrm{Si}, 0.7$ pct Fe, 0.07 pct $\mathrm{Cu}, 1.2 \mathrm{pct}$ $\mathrm{Mn}, 0.1$ pct $\mathrm{Mg}, 0.1 \mathrm{pct} \mathrm{Zn}, 0.1 \mathrm{pct} \mathrm{Ti}$, and balance $\mathrm{Al}$. The as-received hot bands were annealed at 500 centigrade for 2 hours followed by water quenching. The sheets were cold rolled at room temperature by CR (Ra: $0.227 \mu \mathrm{m}$ ) and LTR (Ra: $1.024 \mu \mathrm{m}$ ) using a lubrication oil. The lasertextured roll was processed using rhombus-like lattice pattern (Figure 1). Final thickness reductions of 42, 75, and 90 pct were used. After deformation, the samples were cut into $20 \times 20 \mathrm{~mm}$ to be ready for microstructure observation and texture testing.

Microstructure examinations were carried out using an Olympus (Melville, NY, USA) inverted metallurgical microscopy. The samples were cut from longitudinal sections as defined by the rolling direction (RD) and the normal direction (ND) (refer to specimen geometry in Figure 2). After mechanical grinding and polishing, the samples were electropolished at a voltage of $28 \mathrm{~V}$ D.C for $5 \mathrm{sp}$ using $10 \mathrm{~mL}$ $\mathrm{HClO}_{4}$ and $90 \mathrm{~mL} \mathrm{CH} 3 \mathrm{OH}$ followed by anodizing at a voltage of $20 \mathrm{~V}$ D.C for $15 \mathrm{sp}$ using $38 \mathrm{~mL} \mathrm{H} 2 \mathrm{SO} 4-43 \mathrm{~mL}$ H3PO4-19 mL H2O.

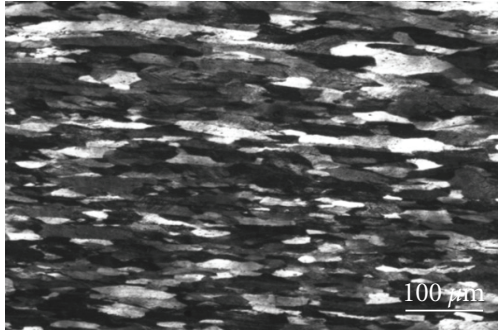

(a)

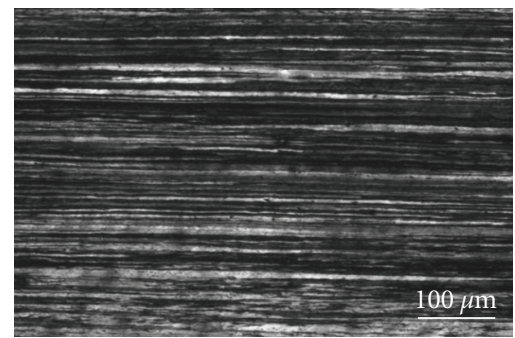

(b)

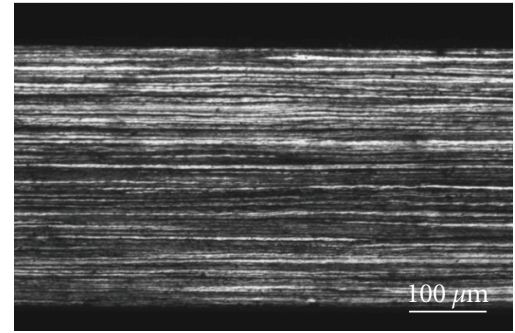

(c)

Figure 3: Polarized optical micrographs of CR rolled 3003 alloy sheets, with the reduction rates of (a) 42 pct, (b) 75 pct, and (c) 90 pct.

The textures were measured by the Schulz reflection method on a PW3040/60-type X-ray goniometer, using $\mathrm{CuK}_{\alpha}$ radiation. The goniometer was operated at $40 \mathrm{KV}$ and $20 \mathrm{~mA}$. Three incomplete pole figures $\{111\},\{200\}$, and $\{220\}$ ( $0 \mathrm{deg} \leq \alpha \leq 75 \mathrm{deg}$ ) were measured. The orientation distribution functions (ODFs) were calculated from the incomplete pole figures using the series expansion method $\left(I_{\max }=16\right)[10]$. The ODFs were presented as plots of constant $\varphi_{2}$ sections with isointensity contours in Euler space defined by the Euler angles $\varphi_{1}, \boldsymbol{\Phi}$, and $\varphi_{2}$.

In order to analyze the through-thickness texture variation, texture measurements were performed at the surface, quarter thickness, and center layers of the LTR rolled sheets. The position was described by a parameter s, which defined the distance between this position and the specimen center divided by the half thickness $(s=0$ means the center and $s=1$ means the surface).

\section{Results and Discussion}

3.1. Microstructures of the Cold Rolling Sheets. Figure 3 shows the transverse section microstructures of 3003 aluminum alloy sheet rolled by CR after rolling reduction of 42,75 , and 


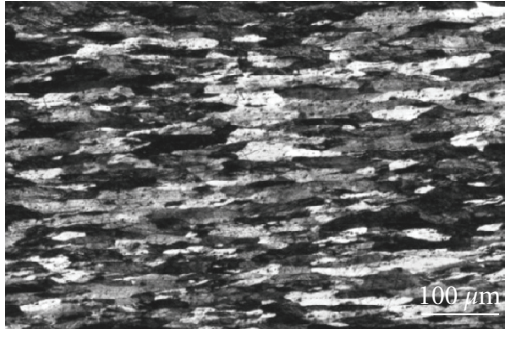

(a)

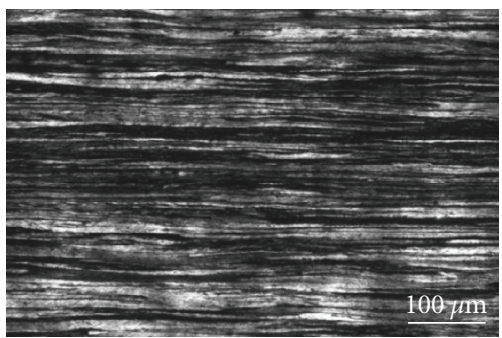

(b)

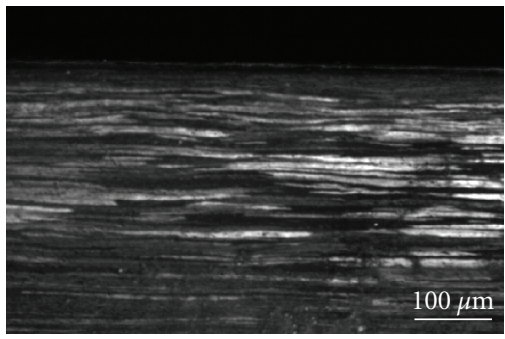

(c)

FIgURe 4: Polarized optical micrographs of LTR rolled 3003 alloy sheets, with the reduction rates of (a) $42 \mathrm{pct}$, (b) $75 \mathrm{pct}$, and (c) 90 pct.

90 pct. A typical pancake grain structure is developed, and the grains are significantly deformed in the RD for the three thickness reduction. With the thickness reduction increasing, a few shear bands can be formed in the deformed grains (Figures 3(b), 3(c)) and severely deformed elongated grains are observed in the alloy after a 90 pct reduction (Figure 3(c)). Figure 4 shows the transverse-section microstructure of LTR rolled sheet by thickness reductions of 42, 75, and 90 pct after rolling. The grain structures of the above materials are similar at 42 pct. However, shear bands can be observed in the deformed grains after rolling by 75 pct with the increase of thickness reductions.

The formation of shear bands is related to the friction between rolls and sheets. During the rolling with LTR, the crater morphology of the textured-roll surface is copied to the sheet (Figure 5), and corresponding concave hole morphology is formed on the surface of aluminum sheet (Figure 6). The imposed deformation on the surface of sheet causes friction in the deformation zone of the sheet and then results in inhomogeneous deformation. At low rolling reduction, the friction is small; the shear concentrates near the surface of the rolls. With the increase of rolling reduction, the shear penetrates into the through thickness and becomes

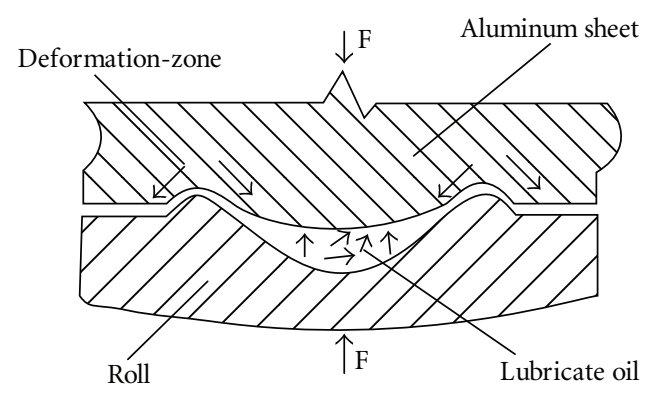

FIGURE 5: Surface relationship of roll and sheet during LTR rolling.

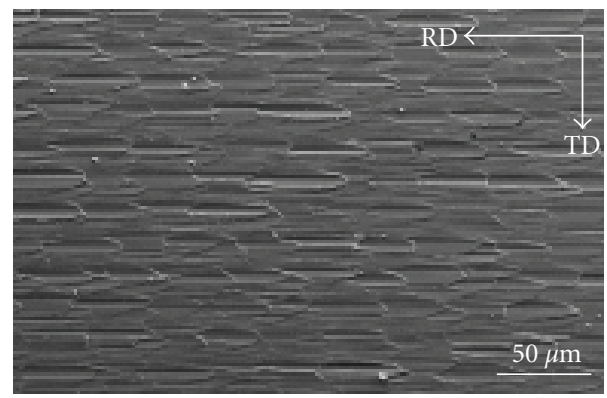

FIGURE 6: Surface morphology of the LTR rolled sheet with $90 \%$ rolling reduction.

noticeably different from CR rolling. This phenomenon is clear in the LTR rolled sheet by 75 pct, in which case, shear bands in the deformed grain can be observed.

The morphology of the sheet surface can improve the rolling and press formability. Firstly, the high coefficient of friction between the roll and the metal surface can reduce the slipping of them. Secondly, the marks on the sheets surface can be served as a pocket of lubricant during a press forming, so the formability can be improved through reducing surface friction.

3.2. Texture Evolution of the Cold Rolling Sheets. The ODFs of CR and LTR rolled materials with cold rolling reductions of 42 pct, 75 pct, and 90 pct are shown in Figures 7(a) and 7(b), respectively. Three sections of $\varphi_{2}=45 \mathrm{deg}, \varphi_{2}=$ $65 \mathrm{deg}$, and $\varphi_{2}=90 \mathrm{deg}$ are selected to show the typical deformation orientation $\mathrm{Bs}, \mathrm{Cu}$, and $\mathrm{S}$ along $\beta$ fiber. Despite the different rolling procedures applied in the present study, the ODFs of all specimens show a well-developed $\beta$ fiber that stems from the $\mathrm{Cu}$-orientation $\{112\}\langle 111\rangle$ through the $S$ orientation $\{123\}\langle 634\rangle$ to the Bs-orientation $\{011\}\langle 211\rangle$. Their intensities increase with the increase of rolling the reduction.

The sheet rolled by CR consists of cube and rolling textures by 42 pct reduction (Figure $7(\mathrm{a})$ ). As the rolling reduction up to $75 \mathrm{pct}$, the texture flows along $\alpha$ fiber to the brass orientation. After 75 pct rolling reduction, the Bs component is well developed during further cold rolling. The $\mathrm{S}$ and $\mathrm{Cu}$ components increase its volume fraction with the increase of thickness reduction. This corresponds directly with the formation law of $\beta$ fiber textures. 

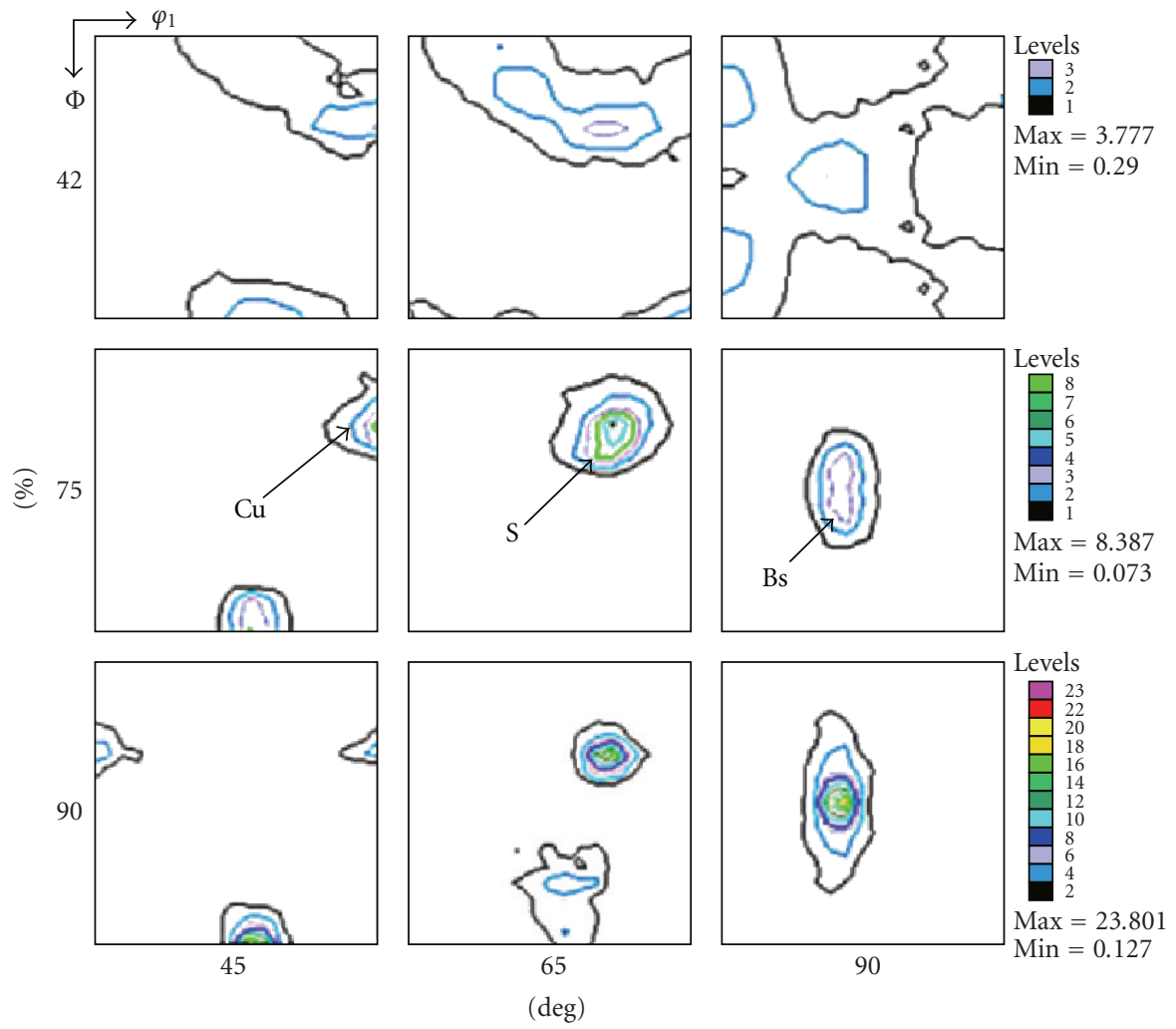

(a)
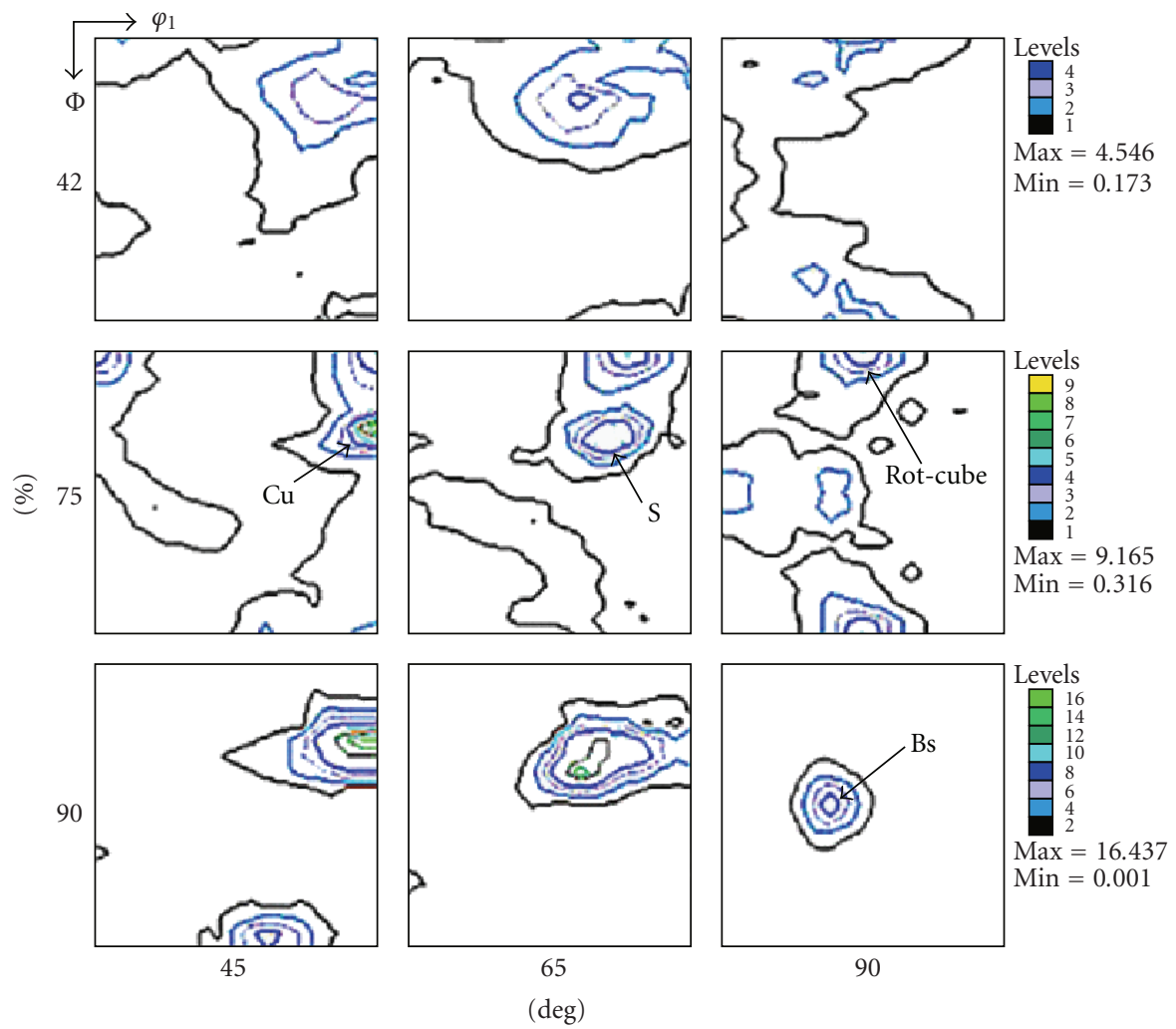

(b)

FIGURE 7: ODFs at sections of $\varphi_{2}=45 \mathrm{deg}, \varphi_{2}=65 \mathrm{deg}$, and $\varphi_{2}=90 \mathrm{deg}$ of 3003 alloy sheets (a) CR and (b) LTR after $42 \mathrm{pct}, 75 \mathrm{pct}$, and 90 pct cold rolling. 


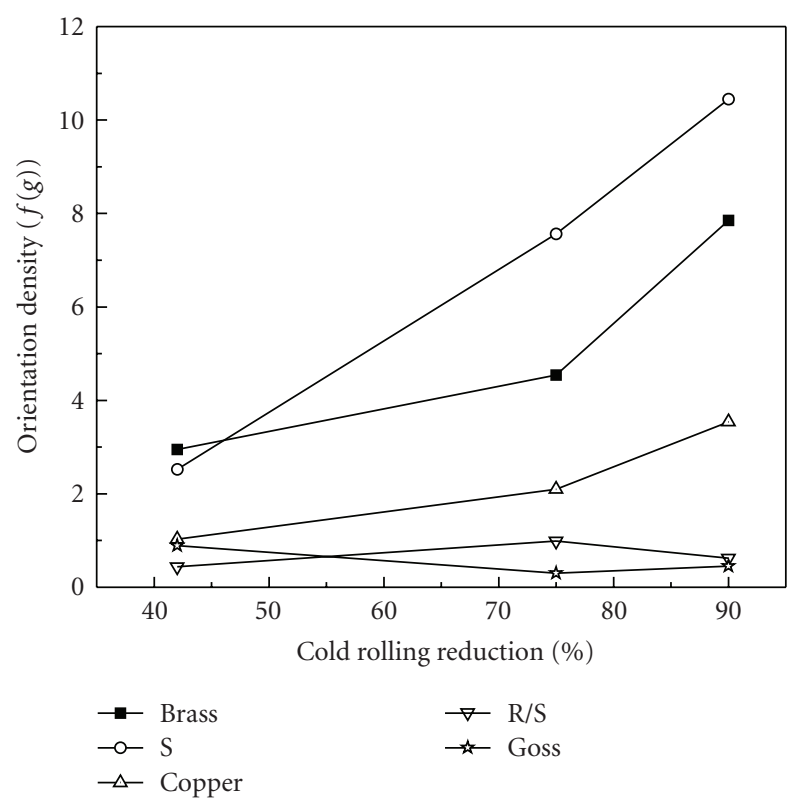

(a)

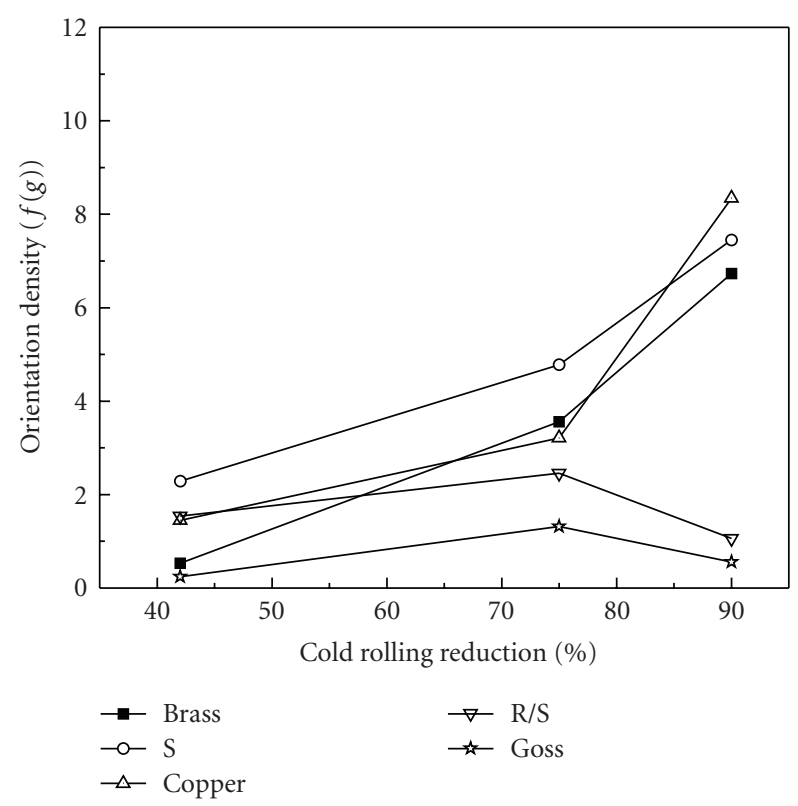

(b)

FIGURE 8: Orientation densities $(\mathrm{f}(\mathrm{g})$ ) of main texture components of 3003 aluminum alloy sheets with different reductions (a) CR rolled sheet, (b) LTR rolled sheet.

The sheet rolled by LTR contains higher volume fraction of rolling and shear textures (Figure $7(\mathrm{~b})$ ). A weak cube orientation $\{001\}\langle 100\rangle$ is observed to be retained after 42 pct rolling reduction, but it is not observed after $75 \mathrm{pct}$ and $90 \mathrm{pct}$ rolling reduction. With the increase of thickness reduction, the intensity of rotated cube orientation decreases, and that of copper orientation increases. After 90 pct reduction, the intensities of $\mathrm{Bs}, \mathrm{Cu}$, and $\mathrm{S}$ components are still high, but these of Goss and rotated cube components are too low to be seen. In general, the ODFs of specimens

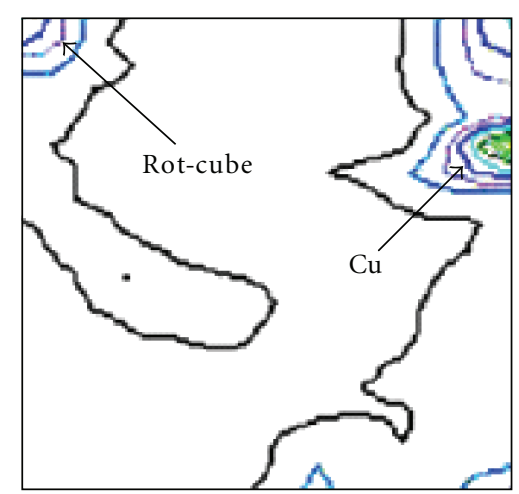

(a)

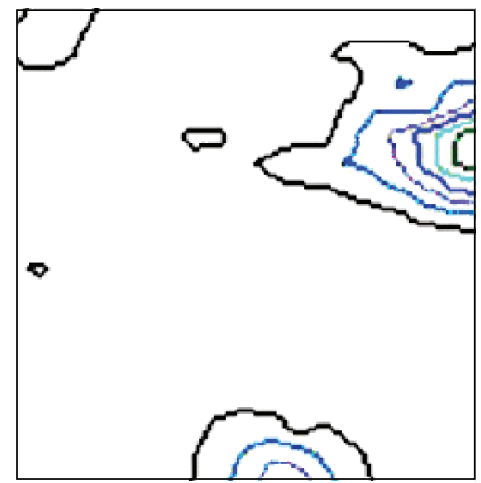

(b)

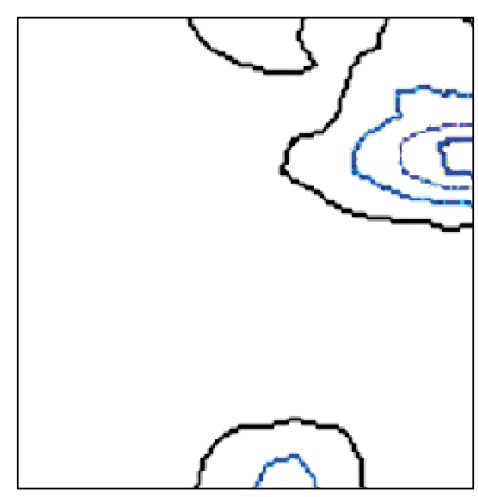

(c)

Figure 9: Constant $\varphi_{2}=45^{\circ}$ section of ODFs in LTR cold rolled sheets with $75 \%$ reduction (a) surface $(s=1)$, (b) intermediate $(s=$ $0.5)$, and (c) center $(s=0)$.

from LTR rolled sheet were similar with those of CR rolled sheet, but they have less intensity and are more scattered.

Figures $8(\mathrm{a})$ and $8(\mathrm{~b})$ show the variation of orientation densities of the main texture components in the CR and LTR rolled sheets with the increase of thickness reduction. For the $\mathrm{S}$ and Bs components in both types of specimens, their orientation densities increase with the increase of thickness reduction. It is interesting to note that the orientation density of the $\mathrm{Cu}$ component of the $\mathrm{CR}$ rolled specimen increases slightly, while that of the LTR rolled specimen increases largely with the increase of thickness reduction. At reductions of more than $75 \%$, the texture is mainly composed of the $\beta$ fiber component. 
Figure 9 shows the through-thickness variation of the texture in LTR rolled aluminum sheets. At 75 pct rolling reduction the main texture at different thickness layers is $\beta$ fiber components. The intensities of main texture components change through the sheet thickness. Comparing the intermediate and center layers, the $\mathrm{Cu}$ component presents the highest intensity in the surface layer and the lowest intensity in the center layer. The formation beginning of the shear texture may be observed on the surface, but it cannot be observed in the intermediate layer $(S=0.5)$ and in the sheet center $(S=0)$.

In CR case, shear strain can be ignored because the friction is small. With the increase of deformation, the metastable goss component evolves into the Bs component, which results in the Bs component increasing. According to Zhou [11], the cube orientation transformed to the Goss orientation and then moved to the Bs-orientation. At the large deformation, the rotation rate of the grains decreases when they pass the $S$ orientation, and most grains stay around the $\mathrm{S}$ orientation. As a result, the density of the $\mathrm{S}$ orientation increases after the deformation.

In the LTR case, inhomogeneous deformation is produced for the high friction between the roll and the sheet, and this can be attributed to the formation of certain shear texture component in the surface layer. The shear component becomes stronger with the increase of deformation. However, it is found that this shear component is unstable [12]. During rolling, the shear texture component $\{001\}\langle 110\rangle$ crystal rotated towards the $\mathrm{Cu}$-orientation. At large reductions the crystal evolved into $\mathrm{Cu}$ component [13]. In addition, under the shear stress, more and more slip and cross slip systems are activated, which drives the grains around $\mathrm{S}$ orientation and finally reach the $\mathrm{Cu}$ position [14]. In this way, the $\mathrm{Cu}$ component in the LTR rolled specimen is greatly enhanced. Meanwhile, the densities of the other components, such as Bs and $S$, are increasing.

\section{Conclusions}

Commercial 3003 alloy sheets subjected to CR and LTR cold rolling with thickness reductions of 42,75 , and $90 \mathrm{pct}$ were studied by the means of microstructure observation and texture analysis. The samples produced from both technologies show a similar grain structure. The LTR rolled sheets contain a relatively higher fraction of shear textures than those of CR rolled sheets in the same processing. At relatively high degree of rolling reduction, the shear textures in LTR rolled sheets disappear accompanying with the increase of copper texture. With the increase of rolling reduction, the $\mathrm{S}$ and Bs components in both specimens strengthen, while the $\mathrm{Cu}$ component weakens in $\mathrm{CR}$ rolled sheet, but it is greatly enhanced in LTR rolled sheet.

At present, it is not completely clear about the evolution of the grain orientation in LTR rolled sheets. However, we found that the different roughness of rolls can influence the evolution of deformation textures. Therefore, the formability behavior of the sheets can be changed. Further research might reveal the evolution of recrystallization texture and the mechanical properties in LTR rolled sheets.

\section{Acknowledgments}

The authors are grateful to acknowledge the financial support of the Key Technologies R \& D Program of Harbin (no. 2006AA4CG021) and the Innovative fund for youth of Harbin (no. 2006RFQGG060).

\section{References}

[1] Z. Li, Y. Mingjiang, W. Liu, and M. Zhong, "Investigation on crater morphology by high repetitive rate YAG laser-induced discharge texturing," Surface and Coatings Technology, vol. 200, no. 14-15, pp. 4493-4499, 2006.

[2] K. Minamida, T. Toshimitu, R. Yamada, and T. Kawamoto, "Laser system for dulling work roll by Q-switched Nd: YAG laser," Nippon Steel Technical Report, no. 46, pp. 30-34, 1990.

[3] Z. G. Lin, J. T. Zhang, Y. Q. Yang, C. W. Qiu, and Y. Q. Zhuang, "Experimental study of laser microprecision treatment of I.C. engine tappet," Tribology Transactions, vol. 37, no. 2, pp. 430432, 1994.

[4] M. Geiger, S. Roth, and W. Becker, "Influence of laserproduced microstructures on the tribological behaviour of ceramics," Surface and Coatings Technology, vol. 100-101, no. 1-3, pp. 17-22, 1998.

[5] J. Hirsch and K. Lücke, "Overview no. 76. Mechanism of deformation and development of rolling textures in polycrystalline f.c.c. metals-I. Description of rolling texture development in homogeneous CuZn alloys," Acta Metallurgica, vol. 36, no. 11, pp. 2863-2882, 1988.

[6] J. Hirsch, E. Nes, and K. Lücke, "Rolling and recrystallization textures in directionally solidified aluminium," Acta Metallurgica, vol. 35, no. 2, pp. 427-438, 1987.

[7] D. A. Hughes, "Microstructural evolution in a non-cell forming metals: Al-Mg," Acta Metallurgica et Materialia, vol. 41, no. 5, pp. 1421-1430, 1993.

[8] H. O. Asbeck and H. Mecking, "Influence of friction and geometry of deformation on texture inhomogeneities during rolling of $\mathrm{Cu}$ single crystals as an example," Materials Science and Engineering, vol. 34, no. 2, pp. 111-119, 1978.

[9] O. Engler, M. Crumbach, and S. Li, "Alloy-dependent rolling texture simulation of aluminium alloys with a graininteraction model," Acta Materialia, vol. 53, no. 8, pp. 22412257, 2005.

[10] H. J. Bunge, Texture Analysis in Materials Science, Butterworths, London, UK, 1982.

[11] Y. Zhou, L. S. Tóth, and K. W. Neale, "On the stability of the ideal orientations of rolling textures for F.C.C. polycrystals," Acta Metallurgica Et Materialia, vol. 40, no. 11, pp. 3179-3193, 1992.

[12] J. Hjelen, R. Orsund, and E. Nes, "On the origin of recrystallization textures in aluminium," Acta Materialia, vol. 39, no. 7, pp. 1377-1404, 1991.

[13] I. L. Dillamore and H. Katoh, "The mechanisms of recrystallization in cubic metals with particular reference to their orientation-dependence," Metal Science, vol. 8, no. 3, pp. 7383, 1974.

[14] C. S. Lee and B. J. Duggan, "A simple theory for the development of inhomogeneous rolling textures," Metallurgical and Materials Transactions A, vol. 22, no. 11, pp. 2637-2643, 1991. 

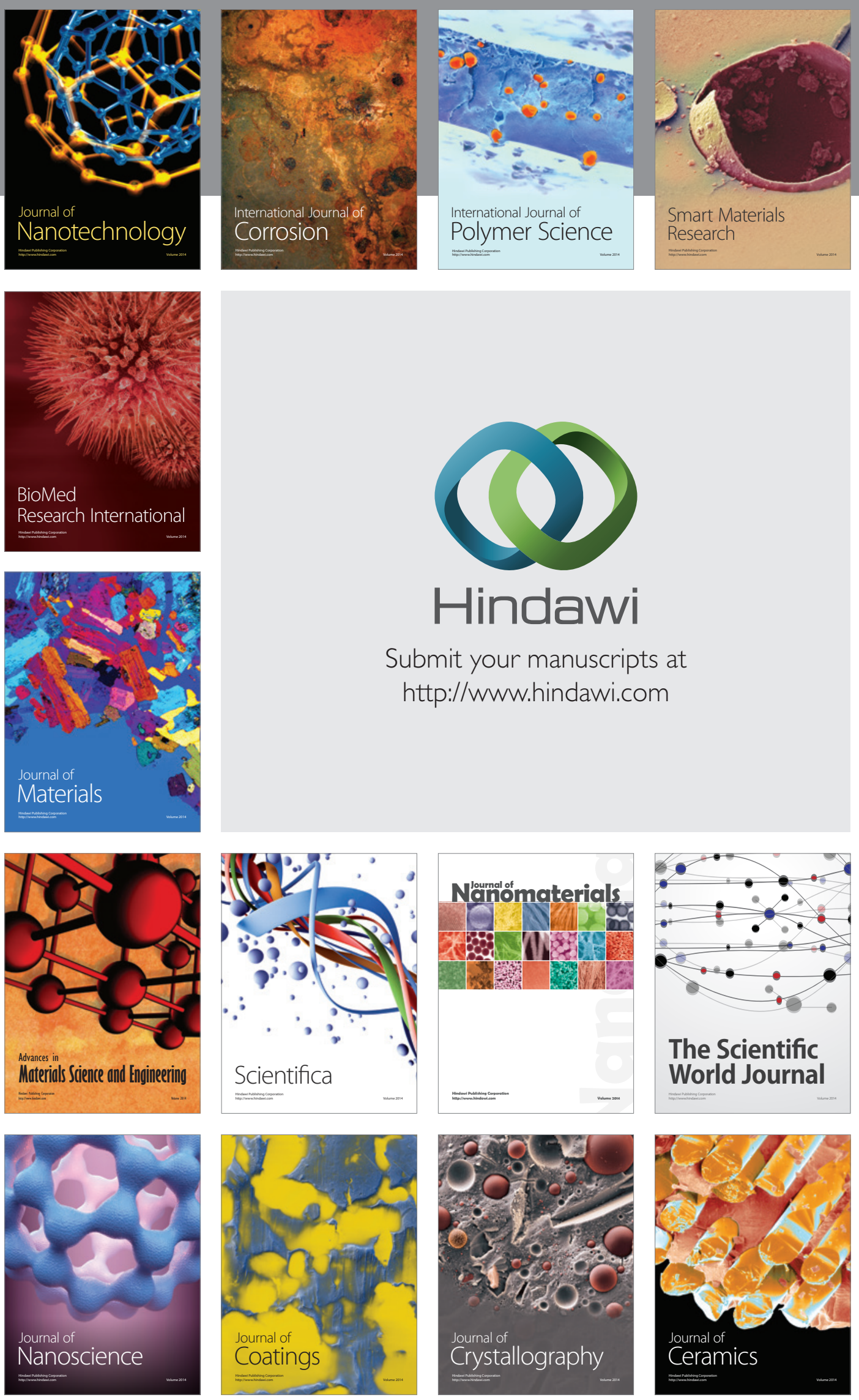

The Scientific World Journal

Submit your manuscripts at

http://www.hindawi.com

\section{World Journal}

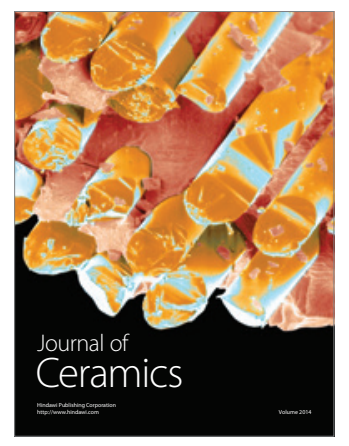

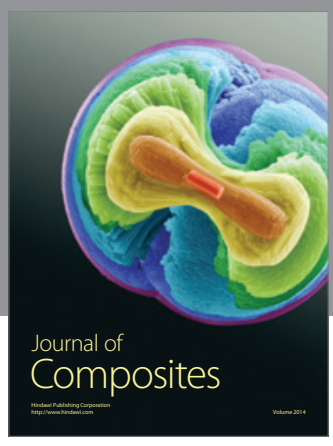
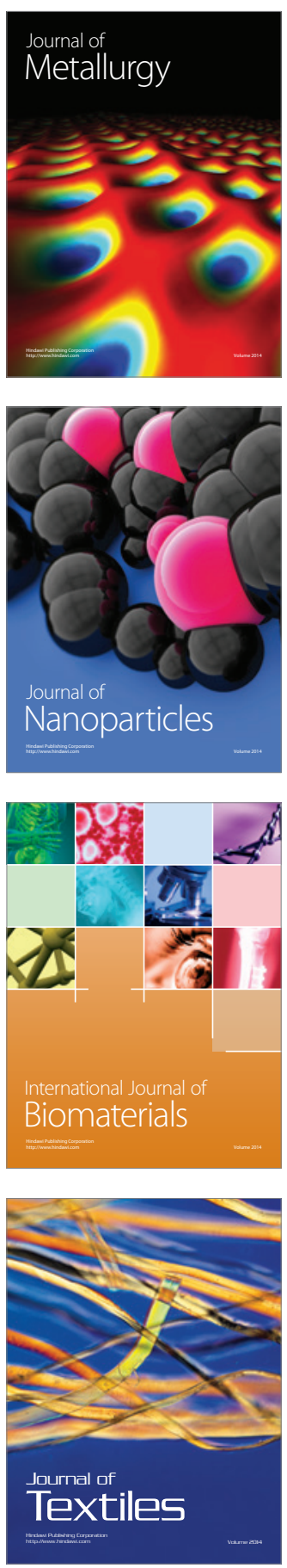